\title{
Information Disclosure in the Renewal of Patents
}

\author{
Claude Crampes* and Corinne Langinier ${ }^{\dagger}$
}

\author{
Revised version \\ July 1997
}

\begin{abstract}
This paper presents a patent choice model allowing strategic decisions in a sequential game with two agents: a patentholder, who knows the characteristics of the market, and a potential entrant who has imperfect information about the value of demand.

We study several Perfect Bayesian Equilibria. We find equilibria where the incumbent prefers not to pay the renewal fee for the patent hoping that it will be interpreted by the challenger as a signal of low market profitability.
\end{abstract}

Keywords: patent, entry, perfect bayesian equilibria.

JEL Classification $=$ D82, L12, 034.

\footnotetext{
*IDEI and GREMAQ, Université de Toulouse I, Place Anatole France - 31042 Toulouse Cedex.

†GREMAQ, Université de Toulouse I, Place Anatole France - 31042 Toulouse Cedex Tél.:+.33.(0)5.61.12.85.71. Fax.:+.33.(0)5.61.22.55.63. - E-mail: langinie@gremaq.univ-tlse1.fr

We would like to thank T. van Dijk, J. Donze, J. Gabszewicz, P. Mahenc, R. Renault and the participants to the 10th ADRES Congress in Strasbourg, the ESEM 96 meeting in Istanbul, the 23 annual EARIE conference in Vienna and two referees of "Les Annales" for their comments. All errors are naturally ours.
} 


\section{Introduction}

Patents are one institutional tool to promote research and development by giving innovative firms the possibility to appropriate the gains from their $R \& D$ efforts. But, it is widely recognized that many firms use the patent system inefficiently or, in some industries, that they even do not use it at all. Also, in countries where the holder of a patent has to pay a renewal fee in order to keep it in force (as it is the case in most European countries), empirical studies have shown that very few patented inventions are protected for the entire legal duration of 20 years. How can these observations be explained and what kind of lessons can they convey for the political economy of promoting innovation?

The first theoretical contribution to the solution of these questions has been to construct models to analyze how private firms design the scope of their patents (length, height and breadth) within the constraints enforced by national or international laws, and, knowing this behavior, how public authorities accommodate these dimensions in order to maximize social welfare ${ }^{1}$. In these works, all economic agents are supposed to share the same set of information on demand and technology or, if one firm has an informational advantage, the others are not able to infer anything on this information by observing its behavior ${ }^{2}$. On the contrary, many contemporary economic models suppose that there exist strong information asymmetries between economic agents and that they use them strategically.

In the present paper, we adopt this viewpoint in analyzing a patenting decision. We focus on the strategic use of private information by the innovator and show how it can justify a weak incentive to protect an innovation. The situation we study is the following: a patentholder, who perfectly knows the characteristics of the market, is facing the possibility of entry by a challenger with poor market information. We consider the case where the patentholder has to pay an annual fee to keep his patent in force. But the decision to pay or not to pay the renewal fee conveys information about the profitability of the market to the challenger. Our purpose is to show how the patentholder can be induced not to pay the renewal fee of his patent in order not to reveal the truth about the market profitability $^{3}$.

\footnotetext{
${ }^{1}$ On the optimal duration of patents and the trade-off between duration and breadth, see Klemperer (1990), Gilbert and Shapiro (1990).

${ }^{2}$ An exception is Horstmann, MacDonald and Slivinski (1985).

${ }^{3} \mathrm{~A}$ similar strategy behavior using advertising expenditures can be found in Bagwell and Ramey (1990). The analysis by Horstmann and alii (1985) is the closest to ours; the main difference is that they do not make explicit the post-entry game and the subsequent profits for both firms.
} 
Patents are presented as property rights allowing the holder to operate markets in a monopolistic way. We focus on their partial endogeneity by showing how the breadth of the protection they convey is influenced by private or public decisions. But patents are also important signals on the inside and outside activity of firms. This second essential feature is included in our model through the asymmetric information on the market value between the patentholder and his challenger.

In section 2, we present some factual and legal motivation for the theoretical model presented in the following sections. In section 3 we develop the hypothesis and timing of the game. As it is a two-period game, we begin by the analysis of the second period equilibrium, namely the investment and production equilibrium, in section 4 . The investment is realized by the entrant in order to differentiate its product to respect the breadth of the incumbent's patent. Then, in section 5 we study the first period equilibrium under symmetric information: at this stage the patentholder must decide to keep or not to keep his patent in force by paying the renewal fee and, knowing this decision the challenger must decide to enter or not to enter the market. Section 6 is devoted to the same problem as in section 5, but assuming that the challenger has probabilistic prior beliefs on the state of the market while the incumbent is perfectly informed. In this framework, we study several Perfect Bayesian Equilibria where the incumbent prefers not to pay the renewal fee. The holder expects that patent renunciation will be interpreted by the challenger as a signal of low market profitability and will prevent its entry.

\section{The signalling value of patents}

Patents are property rights created to stimulate the R\&D activity of firms. They allow to control the entry of competitors in markets where the innovators can develop their sales without the pressure of a fierce competition. With such an obvious (private) quality, one could expect that most innovators would apply for a patent. Actually, it is not the case. In some industries, for instance pulp and paper, cosmetics, motors and generators, computers, semiconductors, aircraft etc..., the high-level R\&D managers give patents bad marks when compared with alternative means of protecting the competitive advantages of new or improved processes and product ${ }^{4}$. Also, in the countries where a necessary condition for patents to remain valid is that the holder pays a yearly renewal fee, for instance in France, a large number of patents are abandoned long before the end of

\footnotetext{
${ }^{4}$ Levin and alii (1987).
} 
the maximal legal duration of 20 years $^{5}$. We can infer from these observations that the innovators have objections to the patent system ${ }^{6}$. The dissemination of technical information is the most recognized failure. Innovators can prefer not to patent because of the legal obligation to disclose the details of their innovation and the consequent risks of imitation by informed competitors. But even if the legal conditions of entry are respected by the challengers, patents can have the adverse effect of signalling the profitability of markets for which they are claimed. This is the point of our model.

In order to motivate the foregoing analysis, we begin by presenting a simple model enlightening the advantages and drawbacks of the legal protection conferred by a patent. Consider a firm which hesitates to patent an innovation while a challenger is likely to enter the market. Let $\Pi_{c e}$ denote the innovator's gross profit when he is protected by a patent (subscript $c$ ) and the challenger is in (subscript $e$ ). Denoting by subscript $\bar{e}$ the situation where the challenger does not enter and by $\bar{c}$ the case where the innovator has no patent protection, it is clear that

$$
\Pi_{c \bar{e}}=\Pi_{\overline{c e}} \geq \Pi_{c e}>\Pi_{\bar{c} e} .
$$

Indeed if there is no entry, gross profits are the same for the incumbent with or without a patent, which explains the equality in (1). But profits are decreased by the entry of a competitor. The decrease is weak, and possibly null, if a patent has been granted, while without any legal protection the incumbent suffers a large loss, which explains the ordering of the inequalities in (1). Now, let $\rho_{c}$ be the probability that an entry occurs when the innovation is patented and $\rho_{\bar{c}}$ when there is no legal protection. Finally the parameter $a$ stands for the cost of patenting.

We want to make explicit the arguments against patenting. Clearly, the innovator is better off without a patent iff

$$
\left(1-\rho_{c}\right) \Pi_{c \bar{e}}+\rho_{c} \Pi_{c e}-a<\left(1-\rho_{\bar{c}}\right) \Pi_{\overline{c e}}+\rho_{\bar{c}} \Pi_{\bar{c} e} .
$$

Using (1), we can rewrite this inequality as

$$
\rho_{\bar{c}}\left(\Pi_{c e}-\Pi_{\bar{c} e}\right)<a+\left(\Pi_{c \bar{e}}-\Pi_{c e}\right)\left(\rho_{c}-\rho_{\bar{c}}\right) .
$$

\footnotetext{
${ }^{5}$ For a recent survey on the use of patent data see Lanjouw, Pakes and Putnam (1996).

${ }^{6}$ However, note that from the social viewpoint private inconveniences can turn out to be advantages. If the innovator decides not to patent and keeps his innovation secret, clearly it is a bad social decision. But, if the innovator enters the market without any protection (neither patent nor secrecy) or if he does not pay the renewal fee of a European patent, this is good for society since the innovation can be used for free by anyone.
} 
Without any signalling effect of the patent, we have $\rho_{\bar{c}}=\rho_{c}=\rho$. Then, (3) is a simple cost-benefit decision rule that compares the expected gain and the cost of the patent:

$$
\rho\left(\Pi_{c e}-\Pi_{\bar{c} e}\right)<a .
$$

Consequently, if we consider that a patent has no ex ante effect, in the sense that it does not change the entry decision of challengers, the explanation for the low success of the patent system is a large cost $a$ and/or a low expected gain $\rho\left(\Pi_{c e}-\Pi_{\bar{c} e}\right)$. For example, the low expected gain argument is the one kept by Schankerman and Pakes (1985) to explain the very short life of a large majority of French patents because the renewal fee $a$ is very $l^{7}{ }^{7}$.

But on the right hand side of condition (3) appears an additional term measuring the pre-entry effect of the patent. Most arguments used by lawyers to promote patents are reflected by the following hypothesis which is standard in the economics of $R \& D^{8}$ : patent is a good dissuasion against entry so that $\rho_{\bar{c}}>\rho_{c}$. Suppose this assertion is true. Then the second term on the right-hand side of (3) is negative, which means that it decreases the advantages of no patenting. Consequently, it cannot be an argument to explain why patents are considered a poor solution to the protection of inventions in many industries.

On the contrary, many practicians argue that the deposit of a patent has the adverse effect of stimulating entry so that

$$
\rho_{\bar{c}}<\rho_{c}
$$

If this is the case, the right hand side is clearly increased, which strengthen the nopatenting solution. The classic explanation of (4) is that the applicant to a patent is constrained by law to give a detailed description of his innovation. Then, potential competitors benefit from this information on the process or product technology and this help them to enter the market, maybe illegally.

A complementary argument against deposit is that patenting transmits an information on the profitability of the market(s) claimed by the holder ${ }^{9}$. Indeed, when a firm learns about a deposit, it can rationally infer that the holder prices the market above the cost to

\footnotetext{
7 "... a large fraction of patents are without any economic value since most of them are abandoned despite very low cost." Schankerman and Pakes (1985), p. 928. Actually the cost of maintaining a patent is much higher than the mere renewal fee because "... there are two aspects to intellectual property...: one is to get patents ... the other thing is to enforce them". Warshofsky (1994), p. 117.

${ }^{8}$ Most economic models adopt the naive assumption that $\rho_{c}=0$, which means that the patent is a perfect protection against any form of imitation.

${ }^{9}$ On the contrary, when challengers have a better information than the patentholder about the market,
} 
enforce the patent. Rather than transmitting this information, the innovator can prefer not to patent.

Such a strategic no-patenting is obviously hard to prove because there is generally a mix of reasons to explain why something does not happen. In some patent cases this desire of no signalling seems to be strongly at work. But of course, the success of a patent or of a no-patent decision is the result of the combined action of all the departments of the firm ${ }^{10}$. The marketing dimension we will stress on from now is only one among the technical, legal, financial and organizational aspects.

The objective of the paper is to present a model explaining why two rational firms can behave in a way that results in (3) and (4). It can be the story of an initial patenting decision like the Kodak and Polaroïd case cited in footnote (10): in this case the tradeoff for the innovator is between to reveal explicitly technical information or to keep it secret while the innovator's information on the market is not necessarily better than the challenger's information. But the complexity of a model dealing with a double asymmetry of information, one on the technology and one on the market would be too high. To keep things simple, we assume here that there is only one asymmetry, that is on the demand function. Moreover, we want to focus on the signalling dimension of patents which means that the informational advantage is to be in favor of the patentee. It results that the model described hereafter fits more the renewal decision problem attached to European patents than to initial patenting decisions: both the patentee and his challenger know the technology since it was publicly disclosed and the patentee has a better knowledge of the market since he is already managing it.

it can be in the interest of the patentee to propose them a licence on the patent. In this case, the game is no longer a signal game but an adverse selection game. See Macho-Stadler and Pérez-Castrillo (1991).

${ }^{10}$ In Warshofsky (1994) one can find a large spectrum of case studies on the strategic use of patents. Several suggest the importance of their signalling drawback. For instance, in the war between Polaroïd and Kodak for the instant photography market, "... [Kodak management] decided [in 1964] that the instant business was not worth a significant effort", p. 71. But in 1968, "... the forerunner of the [Polaroïd] SX-70 film opened Kodak's eyes to the power of Polaroïd's research.... Kodak embarked on an instant program of its own", p. 75. "Whether it was indeed their owe at the brilliance of the Polaroïd research or simply a desire to share in what promised to be a rich market, Kodak's top brass decided to take another look at the instant photography market. What they saw was enticing. Polaroïd sales were booming...", p. 76. "In April 1976, Kodak entered the market", p. 79.

To be complete, we must add that Polaroïd immediately reacted by attacking Kodak for infringing 12 of its patents and that in 1986 Kodak was condemned. "Its losses on the ill-fated adventure were about $\$ 100$ million" (ibid. p. 86). But the quotations clearly show that the patent decision by Polaroïd had generated a revision of Kodak's beliefs resulting in (4). 


\section{The Model}

There are two firms. Firm $H$ holds a patent that gives him a perfect protection on the market $^{11}$. The second firm denoted $E$ is a potential competitor. The conditions of its entry are determined by the patent law. According to most patent laws in Europe, we assume that the holder must pay each year a renewal fee in order to keep his patent in force. If he does not pay it, the patent is permanently cancelled and $E$ can enter the market without any constraint ${ }^{12}$.

In section 6 , the main feature of our model is an information asymmetry on the demand value. We assume that firm $H$ knows whether the market is profitable or not before he pays the renewal fee. The challenger only knows the probability distribution of demand but it can observe the renewal decision by the incumbent. For this reason the incumbent may be induced not to renew his patent despite a high market profitability in order to hide the true value of demand to the challenger.

When the patent is kept in force, entry is not prevented. It is just restricted in the following sense. We assume that the new product has to be sufficiently differentiated from the incumbent's output in order to allow the former innovator to recoup his R\&D expenditures. The investment in product differentiation must be paid by the entrant: this is a way to model the so-called breadth of patents. This requirement is justified in terms of R\&D incentive. For the incumbent, R\&D expenditures belong to the history of the game, so they should not be taken into account in the present public decisions. But if the incumbent cannot recoup these expenditures, future research will be reduced since present innovators anticipate that they will face the same kind of situation in the future.

Both firms have the same production cost function but they differ in their "entry" costs. For the incumbent, the "entry" cost is the renewal fee if he decides to pay it. For the challenger, entry costs are to be paid to install the plant and to advertise the product and additionally, the entrant will have to pay to differentiate its product. We assume that the challenger's entry cost is high enough to prevent it from entering the market when demand is low.

The model is described in a two period game:

\footnotetext{
${ }^{11}$ This means that $H$ is able to detect and to bring an action against any infringer. Entry remains possible as long as the entrant respects the patentee's claims.

${ }^{12}$ We do not consider the case where $E$ files a patent for its own product or process. This patent would be useless because it cannot prevent $H$ from using his innovation and there is no other candidate for entry.
} 
- in the first period, the patentholder $H$ decides whether to pay the renewal fee $(C)$ or to give his patent up $(\bar{C})$. The challenger $E$ observes this decision and decides to enter $(e)$ or not to enter $(\bar{e})$. At the time of these decisions in the asymmetric model of section 6 , the incumbent knows whether demand is high (demand intercept $\alpha_{h}$ ) or low $\left(\alpha_{\ell}\right)$, where $\alpha_{h}>\alpha_{\ell}$, while the entrant only has priors about the States of Nature: $\rho$ denotes the probability that demand is high,

- the second period is an investment and production game where both firms have the same information. If the challenger did not enter, the incumbent has a monopoly position to choose his output. When entry occurs, since the challenger knows the demand, the subgame is a perfect information game where first the entrant chooses its investment in differentiation and second both firms compete in quantities.

In figure 1, we have depicted the first period game. The gains at the bottom of the tree are those resulting from the investment and production decisions of the second period game. They will be determined explicitly in the next section.

Using the classical backward induction argument, we first determine the Cournot equilibrium and the investment of the post-entry subgame. Then, we characterize the Perfect Equilibria (section 5) and Perfect Bayesian Equilibria (section 6) of the complete 
game restricted by the differentiation imposed by the government to protect innovations.

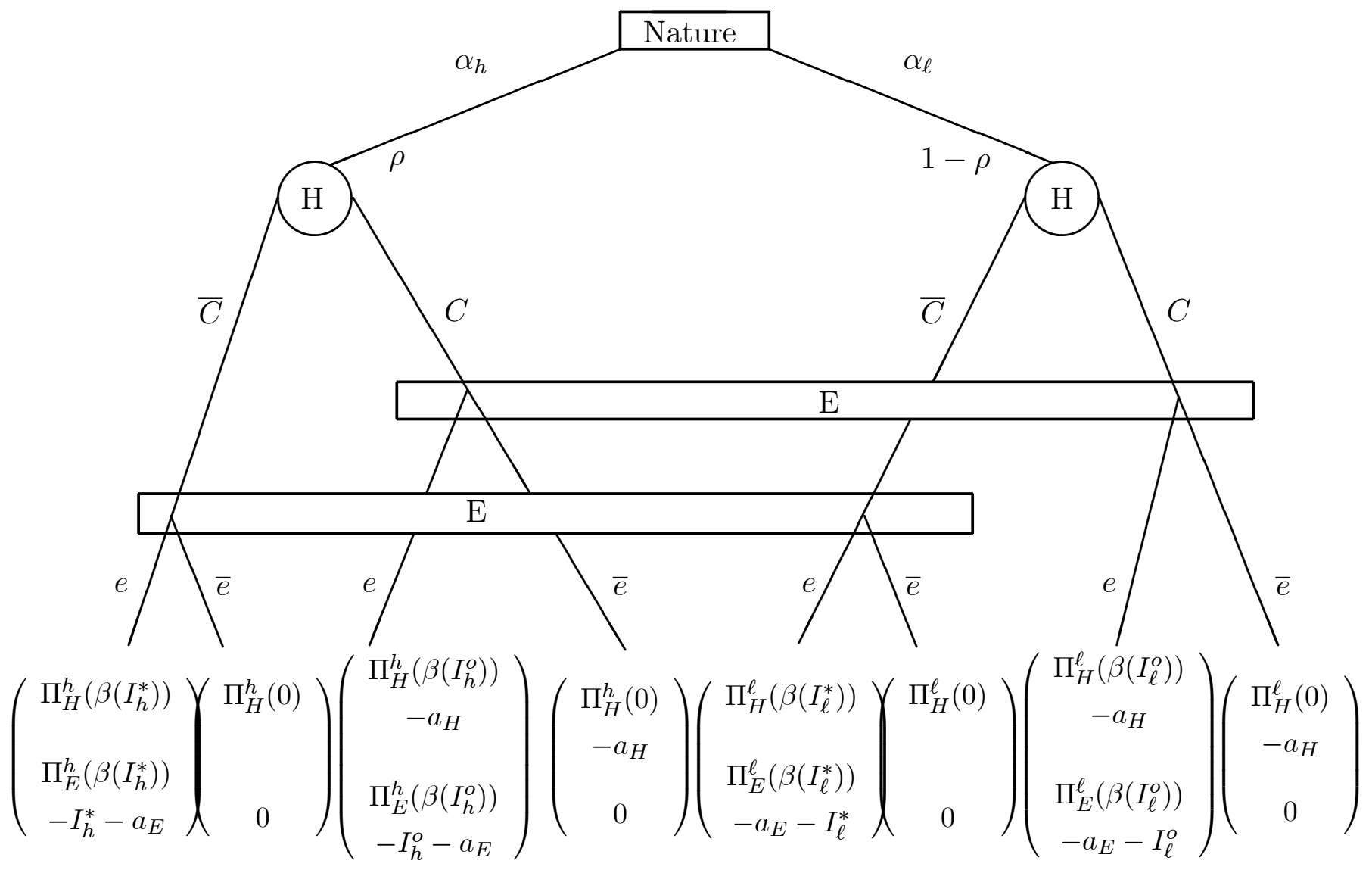

Figure 1: Tree of the first period game

\section{Production Subgame}

We compute the equilibrium quantities sold by the firms when they both have perfect information about the market profitability. Three alternative market situations are possible:

- if the challenger does not enter, the incumbent is a monopolist,

- if the challenger enters and the patent is no longer in force, the market is a duopoly with differentiated products. The differentiation level is determined by the entrant without any restriction before firms produce and it is known by both, 
- finally, if the patent is still in force and the challenger enters the market, it has to respect the patent law, which means not to infringe the incumbent's rights. It is forced to invest in differentiation at least an amount determined by the government. Knowing this differentiation level, both firms then compete in quantities.

\subsection{Choice of Quantities}

The demand for product from each firm $i=H, E$ is represented by:

$$
p_{i}\left(q_{i}, q_{j}\right)=\alpha-q_{i}-\beta q_{j} \quad j \neq i
$$

where $\alpha \in\left\{\alpha_{\ell}, \alpha_{h}\right\}$ is an index of market profitability and $\beta$ is a differentiation parameter, $\beta \in[0,1]$.

$\beta=0$ means that the challenger has entered a market disjointed from the incumbent's market: we have two juxtaposed monopolies ${ }^{13}$.

$\beta=1$ indicates perfect substitutes.

The inverse demand function (5) can be interpreted as the marginal utility of product $i$. The utility function of the representative consumer is

$$
u\left(q_{E}, q_{H}\right)=\alpha\left(q_{E}+q_{H}\right)-\frac{1}{2}\left(q_{E}^{2}+q_{H}^{2}\right)-\beta q_{E} q_{H} .
$$

Finally, we assume that $E$ and $H$ have the same production cost function: let $c$ denote the constant unit cost of production, with $c<\alpha_{\ell}$.

We first determine the socially optimal quantities. Since differentiation has a social value $(\partial u / \partial \beta<0)$ and since the firms have the same production cost, it is Pareto superior to have both firms producing positive quantities.

These quantities are determined by the solution of

$$
\max _{q_{E}, q_{H}} u\left(q_{E}, q_{H}\right)-c\left(q_{E}+q_{H}\right)
$$

and their values are

$$
q_{i}^{0}=\frac{\alpha-c}{1+\beta} \quad i=E, H
$$

\footnotetext{
${ }^{13}$ But even in this case we assume that the private information of the incumbent on $\alpha$ is useful for the challenger in the pre-entry game for evaluating its own market.
} 
Putting these quantities into the social welfare function, we get the maximal social welfare

$$
V\left(q_{E}^{0}, q_{H}^{0}\right)=\frac{(\alpha-c)^{2}}{1+\beta} \operatorname{def}
$$

$=\mathrm{V}(\beta)$.

Second, we consider the case of a private monopoly, which corresponds either to the situation where the challenger decides not to enter or to the situation where the challenger enters but chooses to differentiate its product perfectly $(\beta=0)$.

The incumbent problem is then

$$
\max _{q_{H}}\left(\alpha-q_{H}-c\right) q_{H}
$$

So, he produces $q_{H}^{M}=(\alpha-c) / 2$ and his equilibrium profit is

$$
\Pi_{H}^{M}=\frac{(\alpha-c)^{2}}{4}
$$

As a third case, consider the duopoly structure with differentiated demands (5). Recall that there is perfect information about $\alpha$. Firm $i=E, H$ solves

$$
\max _{q_{i}}\left(\alpha-q_{i}-\beta q_{j}^{*}-c\right) q_{i} \quad j \neq i
$$

It is straightforward to calculate the equilibrium quantities

$$
q_{i}^{*}=\frac{\alpha-c}{2+\beta} \quad i=H, E
$$

and the equilibrium profits are

$$
\Pi_{i}^{*}=\left(\frac{\alpha-c}{2+\beta}\right)^{2} \text { def }
$$

$$
=\prod_{i}(\beta) \text {. }
$$

From (7) and (9) it is easy to check that social welfare as well as private payoffs can be increased by decreasing product homogeneity. 


\subsection{Choice of the Differentiation Level}

\subsubsection{The private choice}

We now assume that the challenger can modify the differentiation parameter by its investment $I$. The investment level is chosen after the entry. Let denote $\beta(I)$ with $\beta^{\prime}(I)<0$ this relation.

When the incumbent has not paid the renewal fee, the entrant is free to choose $I$ to maximize its net profit

$$
\max _{I \geq 0} \Pi_{E}(\beta(I))-I
$$

In order to keep our analysis as simple as possible, we assume that

$$
\beta^{\prime \prime}(I) \leq 0
$$

so that the differentiation investment will necessarily be a corner solution. Either the entrant invests zero so that only the "natural differentiation" $\beta(0)$ will distinguish the products, or, on the contrary, it chooses to differentiate totally ${ }^{14}$ so that $\beta(I)=0$. We define

$$
I_{\max }=\beta^{-1}(0)
$$

Let us denote $I^{*}$ the investment chosen by the entrant. It is defined by

$$
I^{*}= \begin{cases}0 & \text { if } I_{\max }>\Pi_{E}(0)-\Pi_{E}(\beta(0)) \\ I_{\max } & \text { otherwise }\end{cases}
$$

\subsubsection{The breadth requirement}

Without any entry condition, competition from the challenger can result in a bankruptcy for the innovator. On static grounds, this can be welfare-improving if the entrants' profits are higher than the incumbent's profits and/or if the utility of consumers is increased. But this free entry is dangerous for the future since the candidates to new innovations will be dissuaded to invest by the bankruptcy of the incumbent. Consequently, the patent system is designed to promote current research by protecting old researchers. In order not to complicate our model, we assume that this concern is materialized in a constraint to

\footnotetext{
${ }^{14}$ There is perfect differentiation for example when the challenger enters a country on which the patentholder has no claim.
} 
compensate the incumbent for his past research expenditures ${ }^{15}$. The solution we choose is to enforce a sufficient width to the incumbent's patent, that is a low substitutability parameter $\beta$ through a minimal investment in differentiation imposed to the challenger. Denote by $D$ the portion of R\&D expenditures the incumbent has not yet recouped ${ }^{16}$. Using (9), the constraint will be written:

$$
\Pi_{H}(\beta(I))-D \geq 0
$$

Suppose that $\Pi_{H}(0) \geq D \geq \Pi_{H}(\beta(0))^{17}$.

Let $I^{S}$ denote the value of $I$ such that $(12)$ is satisfied as an equality. Since $\Pi^{\prime}(\beta)<0$ and $\beta^{\prime}(I)<0$, inequality $(12)$ can be rewritten

$$
I \geq I^{S}
$$

The constrained investment maximizes the social utility of the agents living at one date subject to constraint (13):

$$
\begin{aligned}
& \max _{I} V(\beta(I))-I \\
& s / c I \geq I^{S}
\end{aligned}
$$

It is easy to check that under the hypothesis (10) the objective function is convex. So, the solution is a corner solution defined by

$$
I^{o}= \begin{cases}I^{S} & \text { if } V\left(\beta\left(I^{S}\right)\right)-I^{S} \geq V(0)-I_{\max } \\ I_{\max } & \text { otherwise }\end{cases}
$$

The comparison between the private investment and the constrained optimal one permits to state the following proposition:

\footnotetext{
15 "The ability of the innovator to capture the surplus generated by his innovation, benefits competition in the long run by encouraging others to innovate as well", Competition Policy and Intellectual Property Rights (OECD, 1989).

${ }^{16}$ It can look curious that the public authority in charge of the patents tailors a specific width for each patentholder. Actually, this is what occurs when patent examiners define ex ante the claims of applicants and when the courts examine the suits for infringement.

${ }^{17} \Pi_{H}(0)=\Pi_{H}\left(\beta\left(I_{\max }\right)\right) \geq D$ means that the initial R\&D choice by the incumbent was at least balanced in a monopoly framework. On the contrary, $D \geq \Pi_{H}(\beta(0))$ means that the innovator would lose money if he was facing a competitor selling a perfect substitute. This is the rationale for a differentiation requirement: the patentholder needs to be protected and the government will not allow the challenger to enter if it does not respect a minimal breadth from the incumbent. An alternative way to write these two hypothesis is $0 \leq I^{S} \leq I_{\max }$.
} 
Proposition $1: I^{o}>I^{*}$ for $I_{\max }>\Pi_{E}(0)-\Pi_{E}(\beta(0))$ and $I^{o}=I^{*}$ otherwise.

The proof is presented in appendix 1.

Actually, if the investment needed for a perfect differentiation $I_{\max }$ is low, the private choice of the challenger is the same as the constrained choice. But, for high values of $I_{m a x}$, the private choice is strictly below the social one.

\section{Final Payoffs and Equilibria under Complete In- formation}

We can now justify the payoffs at the bottom of the tree in figure 1 . The payoffs of the patentholder (resp. the challenger) are on the first (resp. second) line.

For each case where the challenger does not enter $(\bar{e})$, its payoff is 0 and the incumbent is a monopolist (which is equivalent to facing a completely differentiated competitor: $\beta=0$ ) either on a good $(h)$ or on a bad $(\ell)$ market. On the contrary, the decision to enter $(e)$ results in a duopoly situation where both firms earn the same gross profit: $\Pi_{i}^{h}()=.\Pi^{h}($.$) for i=H, E$ if the state of the market is high, and $\Pi_{i}^{\ell}()=.\Pi^{\ell}($.$) if the$ state of the market is low. The value of this gross profit is determined by the level of the investment in differentiation payed by the challenger. When the incumbent has not paid the patent renewal fee $(\bar{C})$, the investment is the one that maximizes the private profit of the challenger, $I_{h}^{*}$ or $I_{\ell}^{*}$. When the patent remains in force $(C)$ the investment is $I^{o}$ described in (14). Note that if $I^{o}=I^{S}$ determined by the equality in (12), its value is contingent on the state of the market since by (9) and (12) the profit needed by the incumbent to recoup his $\mathrm{R} \& \mathrm{D}$ cost is a function of the profitability of the market $\alpha^{18}$.

Finally, we have to subtract from the gross profits the renewal fee $a_{H}$ for the incumbent when he decides to keep his patent in force, the entry cost $a_{E}$ and the differentiation expenses $I$ for the challenger when it decides to enter.

Knowing these net profits, let us review the possible equilibria under complete information.

First we assume that

\footnotetext{
${ }^{18}$ Moreover, one can think that $D$ itself is a function of $\alpha$. If during preceding periods, the incumbent was facing the same State of Nature as in the current period, residual R\&D expenditures depend on this State of Nature. But we assume here that $D$ is a given constant.
} 


$$
\Pi_{E}^{\ell}\left(\beta\left(I_{\ell}^{*}\right)\right)-I_{\ell}^{*}<a_{E}<\Pi_{E}^{h}\left(\beta\left(I_{h}^{o}\right)\right)-I_{h}^{o} .
$$

Because of the first inequality in (15), the challenger will never enter when the market is bad: the low market profitability is such that even if the challenger can freely choose its investment $I_{\ell}^{*}$, the resulting profit is not sufficient to pay the entry cost $a_{E}$. Conversely, as shown by the second inequality, entry is profitable when the market is profitable even if the patent is still active and the investment is determined by legal constraints.

Then, under (15), the challenger enters when $\alpha=\alpha_{h}$ and he does not enter when $\alpha=\alpha_{l}$, whichever the decision of the patentholder. Taking into account this behavior of the challenger, what does the incumbent decide? Facing a low profitability market, he will obviously give the patent up. Paying $a_{H}$ in order to renew the patent would bring no advantage, since the entrant does not enter in this case.

The case with $\alpha=\alpha_{h}$ is more interesting. Anticipating that $E$ will enter, we see in figure 1 that the best decision for the incumbent is to continue iff

$$
\Pi_{H}^{h}\left(\beta\left(I_{h}^{o}\right)\right)-\Pi_{H}^{h}\left(\beta\left(I_{h}^{*}\right)\right) \geq a_{H}
$$

and to abandon otherwise.

As an illustration, because $a_{H} \geq 0$ the equality $I_{h}^{o}=I_{h}^{*}$ is a sufficient (but not necessary) condition for the incumbent to abandon. An alternative way to write $I_{h}^{o}=I_{h}^{*}$ is ${ }^{19}$ :

$$
I_{\max }<\Pi_{E}^{h}(0)-\Pi_{E}^{h}(\beta(0)) .
$$

Particularly we see that if $\beta(0)$ is small, the best choice for the incumbent will be to give up. The reason is that with a "natural" strong level of differentiation, the challenger is not a threat for the incumbent even if it enters the market without any additional expense in differentiation. Consequently, it would be useless to pay a renewal fee just to obtain a very small increase in differentiation by the entrant.

To sum up, we can establish the following proposition:

Proposition 2: The Perfect Equilibrium of the patent-entry game is:

- if $\alpha=\alpha_{\ell}$, the challenger does not enter in any case and the incumbent does not pay for renewing his patent,

\footnotetext{
${ }^{19}$ See figure 2 in appendix 1 and recall that $\Pi_{E}^{j}()=.\Pi_{H}^{j}($.$) for j=h, l$.
} 
- if $\alpha=\alpha_{h}$, the challenger enters in any case and the incumbent pays the renewal fee when (16) is satisfied and does not pay otherwise.

We now turn to the case where the true value of $\alpha$ is unknown by the challenger.

\section{Perfect Bayesian Equilibria}

It is well known that in a sequential game where the follower possesses less information than the leader, the decisions taken by the leader can convey some information valuable to the follower if it can interpret the observations of these decisions. In our model, the decision by the incumbent to pay or not to pay the renewal fee can, under certain circumstances, be interpreted as a signal about the market profitability.

The essential trade-off faced by the incumbent is the following:

- to pay the renewal fee has a "profit effect" which is positive or negative depending on the competition intensity if the challenger enters and on the value of the fee $a_{H}$ (see rule (16)).

- to pay the renewal fee has a "probability effect" which is potentially negative since the observation of the payment will never suggest the challenger that the market is bad. Then, observing that the patent is kept in force can only increase the attractiveness of the market. Consequently, paying increases the probability that $H$ will face a competitor.

So, when the "profit effect" is negative, both effects work in the same direction: the incumbent is better off without the patent independently of the state of the market and we have a pooling equilibrium (see below 6.1). When the "profit effect" is positive, it works

against the "probability effect" and the incumbent has some incentives to pay when the market is profitable and not to pay when the market is bad. But, as shown in paragraph 6.2 , this incentive is not sufficient to generate separating equilibria. Consequently, in paragraph 6.3, we analyze the characteristics of semi-separating equilibria.

As the analysis shows, there exist a large number of different equilibria for alternative values of the parameters. It is out of the scope of the present paper to give a complete 
description of all these equilibria. As we are essentially interested in the behavior of an incumbent trying to blockade the entry of a competitor, we will focus on the equilibria where the patentholder while knowing that the market is highly profitable prefers not to pay the renewal fee.

\subsection{The pooling equilibria}

In a pooling equilibrium, the incumbent chooses the same strategy independently of the State of Nature. So the challenger cannot update its beliefs and it has to take its decision on the basis of the priors. The value of the priors is essential for the existence of a pooling equilibrium since if the challenger initially thinks that the market is profitable, it will be difficult to make it change its mind by a simple decision of no-patenting. Define ${ }^{20}$

$$
=\frac{I_{\ell}^{*}+a_{E}-\Pi_{E}^{\ell}\left(\beta\left(I_{\ell}^{*}\right)\right)}{\Pi_{E}^{h}\left(\beta\left(I_{h}^{*}\right)\right)-I_{h}^{*}-\Pi_{E}^{\ell}\left(\beta\left(I_{\ell}^{*}\right)\right)+I_{\ell}^{*}},
$$

and denote $d_{H}(\alpha)$ the decision by the patentholder, and $d_{E}\left(d_{H}\right)$ the decision by the challenger.

Proposition 3 : For $\rho \leq \rho^{*}$, there exists a pooling equilibrium defined by

$$
\begin{aligned}
& d_{H}(\alpha)=\bar{C} \quad \forall \alpha, \\
& d_{E}(\bar{C})=\bar{e}, d_{E}(C)=e \\
& \operatorname{Prob}\left\{\alpha=\alpha_{h} / d_{H}=C\right\}=1
\end{aligned}
$$

The intuition behind this proposition is the following ${ }^{21}$. When $\rho$ is small, the chances that the challenger enters are weak. To pay the renewal fee will be a good protection if entry occurs ("profit effect") but it will also increase the incentive to enter. Consequently, the incumbent is better off without renewing in any case. The challenger cannot revise its priors and, since $\rho \leq \rho^{*}$, its expected profits are negative. So, when observing $d_{H}=\bar{C}$, it cannot infer the true value of $\alpha$ and it decides not to enter. Now, what occurs if it observes the out-of-equilibrium decision $d_{H}=C$, that is a decision to pay the fee by the

\footnotetext{
${ }^{20} \rho^{*}$ is the value of the prior such that the entrant has a zero expected profit when entering a non protected market.

${ }^{21}$ For formal proofs, see Appendix 2.
} 
patentholder? To keep $(\bar{C}, \bar{e})$ as the equilibrium path, we must define a revision rule of the prior such that it cannot be in the interest of the holder to deviate. With the proposed rule $\operatorname{Prob}\left\{\alpha=\alpha_{h} / d_{H}=C\right\}=1$, any deviation by the incumbent induce an entry $\left(d_{E}(C)=e\right)$ which is clearly bad for him.

Proposition $4:$ For $\rho>\rho^{*}$ and

$$
a_{H}>\max \left\{\Pi_{H}^{h}\left(\beta\left(I_{h}^{o}\right)\right)-\Pi_{H}^{h}\left(\beta\left(I_{h}^{*}\right)\right), \Pi_{H}^{h}(0)-\Pi_{H}^{h}\left(\beta\left(I_{h}^{*}\right)\right)\right\}
$$

there exists a pooling equilibrium where

$$
\begin{array}{ll}
d_{H}(\alpha)=\bar{C} & \forall \alpha, \\
d_{E}\left(d_{H}\right)=e & \forall d_{H} \\
\operatorname{Prob}\left\{\alpha=\alpha_{h} / d_{H}=C\right\}=1 &
\end{array}
$$

In this case, it would be too costly for the incumbent to prevent the challenger from entering. The renewal fee $a_{H}$ is so high, or equivalently the natural differentiation is so strong $(\beta(0)$ close to 0$)$ that the patentholder prefers not to pay ${ }^{22}$. On the basis of the priors, the challenger enters in any case and any revision of the prior beliefs on the basis of an out-of-equilibrium observation would be without any effect on the holder's gains but would cost him $a_{H}$. So the patentholder does not deviate.

There exist other pooling equilibria, those where the incumbent pays the renewal fee for any value of the market profitability. In this type of equilibrium, an incumbent who knows that the market is bad mimics the behavior of a firm selling on a rich market. This can only increase the chances to attract a challenger. Actually, it is essentially justified by a low renewal fee $a_{H}$ as compared to the high profits expected from the protection. As we saw with the observations of Schankerman and Pakes (1985), few innovators are concerned by such a non contingent behavior. A more precise analysis of this behavior would need a clear description of the out-of-equilibrium decisions, particularly the rationale for infringements and legal $\operatorname{attack}^{23}$.

\footnotetext{
${ }^{22}$ When $\beta(0)$ is close to $0, \beta\left(I_{h}^{o}\right)$ and $\beta\left(I_{h}^{*}\right)$ are close to 0 so that the differences in the right hand side of (19) are very small.

${ }^{23}$ The Polaroïd vs. Kodak case presented in footnote (10) is a good example of such a situation: entry is "forbidden", nevertheless there is an entry, then the patentholder goes to trial.
} 


\subsection{The non existence of a separating equilibrium}

A separating equilibrium requires that the challenger can interpret unambiguously the actions it observed from the patentholder. In particular, the non payment of the renewal fee should clearly mean that the market is non profitable. But if the patentholder knows that the follower will interpret the no-renewal as a signal of low profitability and consequently will decide not to enter, it is in his interest not to pay when the market is of type $\alpha_{h}$. Then, he will never choose to renew his patent, so that there cannot exist a separating equilibrium.

\subsection{The semi-separating equilibria}

The preceding development suggests that we can find semi-separating equilibria, i.e. equilibria in which the incumbent will not take the same decision irrespective of the market characteristics (there is no complete pooling) but nevertheless the challenger cannot dis-

cover for sure the missing information by observing the incumbent (there is no complete separation).

Several semi-separation equilibria are possible. We just consider the following one, where $\pi_{H}$ is the probability that the holder abandons his patent and $\pi_{E}$ is the probability that the challenger enters.

Proposition 5: For $\rho>\rho^{*}$ and

$$
a_{H}<\Pi_{H}^{h}\left(\beta\left(I_{h}^{o}\right)\right)-\Pi_{H}^{h}\left(\beta\left(I_{h}^{*}\right)\right)
$$

there exists a semi-separating equilibrium where

$$
\begin{aligned}
& d_{H}(\alpha)= \begin{cases}(\bar{C}, C ; 1,0) & \text { if } \alpha=\alpha_{\ell} \\
\left(\bar{C}, C ; \pi_{H}, 1-\pi_{H}\right) & \text { if } \alpha=\alpha_{h}\end{cases} \\
& d_{E}\left(d_{H}\right)= \begin{cases}(e, \bar{e} ; 1,0) & \text { if } d_{H}=C \\
\left(e, \bar{e} ; \pi_{E}, 1-\pi_{E}\right) & \text { if } d_{H}=\bar{C}\end{cases} \\
& \operatorname{Prob}\left\{\alpha=\alpha_{h} / d_{H}=C\right\}=1 \\
& \operatorname{Prob}\left\{\alpha=\alpha_{h} / d_{H}=\bar{C}\right\}=\frac{\rho \pi_{H}}{\rho \pi_{H}+(1-\rho)} .
\end{aligned}
$$

When the market is low-valued, the incumbent decides not to pay the fee. But this can also occur when the market is good. Consequently, when it observes a no-renewal, 
the challenger cannot be quite sure that the market is bad. It can just perform a bayesian revision of its priors. It is only when the challenger observes the payment of the fee that it can be sure that the market has a high value and that it decides to enter with probability 1.

When the incumbent knows that the market type is $\alpha_{h}$, he plays a mixed strategy: he decides to give up the patent with a probability

$$
=\operatorname{Prob}\left\{\bar{C} / \alpha_{h}\right\}=\frac{1-\rho}{\rho} \frac{a_{E}+I_{\ell}^{*}-\Pi_{E}^{\ell}\left(\beta\left(I_{\ell}^{*}\right)\right)}{\Pi_{E}^{h}\left(\beta\left(I_{h}^{*}\right)\right)-I_{h}^{*}-a_{E}} .
$$

The challenger who observes that the patent is no longer active decides to enter with probability

$$
=\operatorname{Prob}\{\mathrm{e} / \bar{C}\}=\frac{\Pi_{H}^{h}(0)-\Pi_{H}^{h}\left(\beta\left(I_{h}^{o}\right)\right)+a_{H}}{\Pi_{H}^{h}(0)-\Pi_{H}^{h}\left(\beta\left(I_{h}^{*}\right)\right)} .
$$

Given (21), the challenger is indifferent between entry and no entry when it observes that the patent is no longer in force. Given (22) the patentholder is indifferent between paying or not paying the fee when the market is good.

The bayesian rule to revise the prior when observing that the patent is abandoned is

$$
\begin{aligned}
\operatorname{Prob}\left\{\alpha_{h} / \bar{C}\right\} & =\frac{\operatorname{Prob}\left\{\bar{C} / \alpha_{h}\right\} \rho}{\operatorname{Prob}\left\{\bar{C} / \alpha_{h}\right\} \rho+\operatorname{Prob}\left\{\bar{C} / \alpha_{\ell}\right\}(1-\rho)} \\
& =\frac{\rho \pi_{H}}{\rho \pi_{H}+(1-\rho)}
\end{aligned}
$$

since the incumbent plays $\bar{C}$ with probability one when he observes $\alpha_{\ell}$.

As compared with the equilibrium in proposition 3, we see that this one needs a high value of the prior beliefs $\rho$. Consequently, here a complete pooling to try to restrict any entry is not possible since the challenger thinks that the market is good with a high probability.

As compared with the equilibrium in proposition 4 , we see that the renewal fee is to be low and/or $\beta($.$) is to be high which means a weak natural differentiation level. This$ explains that the incumbent has some interest in keeping the patent in force even if that gives the challenger a reason for entering. 


\section{Conclusion}

When a patentholder possesses private information about the value of demand, he knows that his behavior may affect the entry decision of the challenger. Thus, the decision to pay the renewal fee to maintain the patent active can be used by the holder as a strategic instrument.

In a non strategic framework, not to pay the renewal fee simply means that the expected benefits from the patent (monopoly profit minus duopoly profit) are less than the expected value of its costs. These costs are larger than the mere administrative fees because they include the expected expenditures for monitoring the markets and suing for the infringements. For rational agents, the (publicly observed) payment of the fee should be interpreted as a commitment to sue firms who infringe. Conversely, the non payment should mean that the patent is not worth all the (partially unobserved) incurred costs. But, because of its incomplete information on demand and of the lack of observability of some incumbent's expenditures, the challenger can never be sure of the reason why the patentholder abandons his exclusive right. Thus, the strategic signalling effect consists in abandoning a profitable patent in order to convince the challenger that the market is bad. Because of information acquisition on the markets, such a strategic behavior is more likely at the very beginning of the patent life: the innovator applies for a patent and when he gets it (usually two years later), he does not keep it in force, which could mean that the market studies eventually revealed an unprofitable activity.

The trade-off is between the profit advantages of the patent that obliges any entrant to differentiate its product and the risk to attract a challenger by signalling a highly profitable market. There exist numerous equilibria among which we have considered some. In particular, we have found that when the challenger has low beliefs on the market profitability, the incumbent can prefer not to pay the renewal fee even if the market is favorable, in order to send a bad "signal" to the challenger.

In mixed strategies, the patentholder decides not to pay the renewal fee when the market is bad and to randomize his decision when the market is good. When the challenger observes that the incumbent pays the renewal fee, it knows that the market is good and decides to enter. But, when it observes that the incumbent gave his patent up, it decides to enter or not the market on the basis of revised probabilities.

One can conclude that this signalling feature of the renewal decision is an incentive to shorten the actual duration of patents. This can be a piece of explanation for the 
surprising short life observed for most patents, despite the very low value of fees at the beginning of their life. 


\section{References}

[1] Bagwell K. and G. Ramey (1990) "Advertising and pricing to deter or accomodate entry when demand is unknown", IJIO, 81, 93-113.

[2] van Dijk T. (1995) "Innovation incentives through third degree price discrimination in a model of patent breadth", Economic letters, 47, 431-435.

[3] Fudenberg D. and J. Tirole (1986) "Noncooperative game theory for industrial organization : an introduction and overview", in Handbook of Industrial of Organization, ed. Schmalensee et R. Willig.

[4] Gallini N.(1991) "Patent policy and costly imitation", Rand Journal of Economics, 23, 52-63.

[5] Gilbert R. et C. Shapiro (1990) "Optimal patent length and breadth", Rand Journal of Economics, 21, 106-112.

[6] Horstmann I., G.M. MacDonald and A. Slivinski (1985) "Patent as information transfer mechanisms: To patent or (maybe) not to patent", Journal of Political Economy, 93, 837-858.

[7] Klemperer P. (1990) "How broad should the scope of patent protection be ?", Rand Journal of Economics,, 21, 113-130.

[8] Lanjouw J., A. Pakes and J. Putnam (1996) "How to count patents and value intellectual property: uses of patent renewal and application data", Working paper 5741.

[9] Levin R.C., A.K. Klevorick, R.R. Nelson and S.G. Winter (1987) "Appropriating the returns from industrial research and development", Brookings papers on economic activity, 3, 783-831.

[10] Macho-Stadler I. and D. Pérez-Castrillo (1991) "Contrats de licences et asymétrie d'information", Annales d'Economie et Statistique, 24, 189-208.

[11] Pakes A. (1985) "On patent, R\&D and the stock market rate of return", Journal of Political Economy, 93, 390-409.

[12] Schankerman M. and A. Pakes (1985) "Valeur et Obsolescence des brevets", Revue Economique,36, 917-941. 
[13] Scotchmer S. and J. Green (1990) "Novelty and disclosure in patent law", RAND Journal of Economics, 21, 131-146.

[14] Warshofsky F. (1994) The Patent Wars. The battle to own the world's technology, John Wiley, Sons, Inc., New York. 


\section{APPENDIX 1:}

\section{The breadth requirement}

\section{Proof of proposition 1.}

We have to show that $I^{o} \geq I^{*}$.

First, we determine the "static optimum", which is the investment that maximizes the social utility of the agents living at one date without any constraint

$$
\max _{I \geq 0} V(\beta(I))-I
$$

This is a convex objective function and the solution is a corner solution:

$$
I^{s o}= \begin{cases}0 & \text { if } I_{\max }>V(0)-V(\beta(0)) \\ I_{\max } & \text { otherwise }\end{cases}
$$

$I^{o}$ is the solution to the same problem but with the additional constraint (13): $I \geq I^{S}$. Clearly, the exact value of $I^{o}$ cannot be known and compared with $I^{s o}$ without expliciting the functional shape of the $V($.$) and \beta($.$) functions. But because of the constraint (13) it is$ evident that $I^{o}$ is generically greater than $I^{o}$. On the other hand, from $V(0)-V(\beta(0))>$ $\Pi_{E}(0)-\Pi_{E}(\beta(0))$ it is evident that $I^{o} \geq I^{*}$. Consequently, we obtain $I^{o} \geq I^{*}$.

We illustrate this result in figure 2 where the levels of optimal private investment $I^{*}$ and of constrained investment $I^{o}$ are drawn as a function of $I_{\max }$.

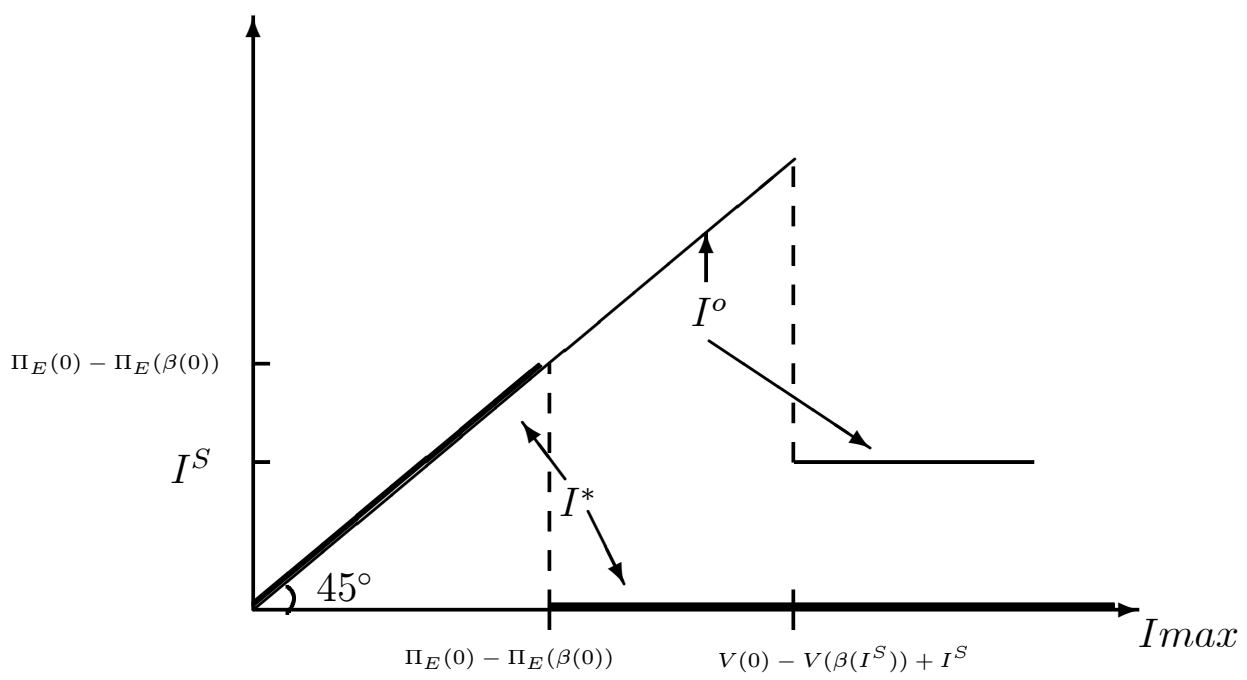

Figure 2: Private and social values of the investment in differentiation 


\section{APPENDIX 2:}

\section{Perfect Bayesian Equilibria}

\section{Proof of propositions 3, 4 and 5 .}

\subsection{Pooling Equilibria}

We determine the pooling equilibrium when the incumbent decides not to pay the renewal fee whatever the value of the market.

The challenger observes nothing and then its posterior belief is equal to its prior $\mu=\rho$. In order to keep the proof as simple as possible, we simplify the notation: $\Pi_{E}^{j}()=.\Pi_{H}^{j}()=$. $\Pi^{j}($.$) with j=h, l$.

It decides not to enter the market if:

$$
\begin{gathered}
\rho\left[\Pi^{h}\left(\beta\left(I_{h}^{*}\right)\right)-a_{E}-I_{h}^{*}\right]+(1-\rho)\left[\Pi^{\ell}\left(\beta\left(I_{\ell}^{*}\right)\right)-I_{\ell}^{*}-a_{E}\right]<0 \\
\Leftrightarrow \rho<\frac{I_{\ell}^{*}+a_{E}-\Pi^{\ell}\left(\beta\left(I_{\ell}^{*}\right)\right)}{\Pi^{h}\left(\beta\left(I_{h}^{*}\right)\right)-I_{h}^{*}-\left[\Pi^{\ell}\left(\beta\left(I_{\ell}^{*}\right)\right)-I_{\ell}^{*}\right)}=\rho^{*} .
\end{gathered}
$$

Then, with an out-of-equilibrium belief $\operatorname{prob}\left\{\alpha=\alpha_{h} / d_{H}=C\right\}=1$, the incumbent will not deviate because $\Pi^{h}(0)>\Pi^{h}(0)-a_{H}$ and $\Pi^{h}(0)>\Pi^{h}\left(\beta\left(I_{h}^{o}\right)\right)-a_{H}$.

We can conclude that for values of $\rho \leq \rho^{*}$, there exists a pooling equilibrium for an out-of-equilibrium belief $\operatorname{prob}\left\{\alpha=\alpha_{h} / d_{H}=C\right\}=1$ (proposition 3).

The challenger decides to enter the market if $\rho>\rho^{*}$.

And the incumbent will deviate if

$$
\begin{gathered}
\Pi^{h}\left(\beta\left(I_{h}^{*}\right)\right)<\Pi^{h}\left(\beta\left(I_{h}^{o}\right)\right)-a_{H} \\
\quad \text { or } \Pi^{h}\left(\beta\left(I_{h}^{*}\right)\right)<\Pi^{h}(0)-a_{H}
\end{gathered}
$$

then, if (24) or (25) are satisfied, there is no equilibrium; whereas if (24) and (25) are not satisfied, (i.e. $\left.a_{T}>\max \left\{\Pi^{h}\left(\beta\left(I_{h}^{o}\right)\right)-\Pi^{h}\left(\beta\left(I_{h}^{*}\right)\right), \Pi^{h}(0)-\Pi^{h}\left(\beta\left(I_{h}^{*}\right)\right)\right\}\right)$ there is a pooling equilibrium for an out-of-equilibrium belief $\operatorname{prob}\left\{\alpha=\alpha_{h} / d_{H}=C\right\}=1$ (Proposition 4). 


\subsection{Separating Equilibria}

If the firm $H$ decides to pay the renewal fee when the market is favorable and not to pay the renewal fee otherwise, the challenger knows the value of demand from the mere observation of the action undertaken by $H$. Its posterior $\mu$ (on good value demand) is equal to one. Then, if the firm $E$ observes that the incumbent pays the renewal fee, it decides to enter the market (because the market is favorable) and if $E$ observes that $H$ gives his patent up, it doesn't enter.

But, when the market is favorable, and the firm $E$ decides to enter, the patentholder will deviate because

$$
\Pi^{h}\left(\beta\left(I_{h}^{o}\right)\right)-a_{H}<\Pi^{h}(0) .
$$

Then, it is not a separating equilibrium.

Conversely, if the patentholder decides to give his patent up when the market is favorable, and to pay the renewal fee otherwise, the challenger discovers the market value. It decides to enter the market when $H$ abandons his patent, and not to enter otherwise. But, the firm $H$ will deviate when the challenger doesn't enter because:

$$
\Pi^{h}(0)-a_{H}<\Pi^{h}(0) .
$$

Thus, we find that there is no separating equilibrium.

\subsection{Semi-Separating Equilibria}

In mixed strategies, we can calculate some semi-separating equilibria. Among all the equilibria, we determine the semi-separating equilibrium that seems most appealing on economic grounds. If the market is bad, the incumbent always gives his patent up, whereas, when the market is favorable, he decides to randomize his renewal decision. He keeps his patent in force with probability $\left(1-\pi_{H}\right)$, and he doesn't pay the renewal fee with the complementary probability $\pi_{H}$.

If the strategy "keep the patent in force" $(C)$ is observed, the value of the market is good. Then, the entrant decides to enter the market. When the market is bad the incumbent must be indifferent between "give his patent up" $(\bar{C})$ or "keep his patent in force" $(C)$. It exists a probability $\pi_{E}$ def 
$=\operatorname{Prob}\{\mathrm{e} / \bar{C}\}$ such that:

$$
\begin{gathered}
\pi_{E}\left[\Pi^{h}\left(\beta\left(I_{h}^{*}\right)\right)\right]+\left(1-\pi_{E}\right) \Pi^{h}(0)=\Pi^{h}\left(\beta\left(I_{h}^{o}\right)\right)-a_{H} \\
\Leftrightarrow \pi_{E}=\frac{\Pi^{h}(0)-\Pi^{h}\left(\beta\left(I_{h}^{o}\right)\right)+a_{H}}{\Pi^{h}(0)-\Pi^{h}\left(\beta\left(I_{h}^{*}\right)\right)} .
\end{gathered}
$$

This probability exists and belong to $[0,1]$ if:

$$
\Pi^{h}\left(\beta\left(I_{h}^{*}\right)\right)<\Pi^{h}\left(\beta\left(I_{h}^{o}\right)\right)-a_{H}
$$

The profit of the firm $E$ if it enters $(e)$ after observing that the incumbent abandoned his patent $(\bar{C})$ is:

$$
\mu\left(\alpha_{h} / \bar{C}\right)\left[\Pi^{h}\left(\beta\left(I_{h}^{*}\right)\right)-I_{h}^{*}-a_{E}\right]+\left[1-\mu\left(\alpha_{h} / \bar{C}\right)\right]\left[\Pi^{\ell}\left(\beta\left(I_{\ell}^{*}\right)\right)-I_{\ell}^{*}-a_{E}\right]
$$

whereas the profit of the entrant if it decides not to enter $(\bar{e})$, when it observes that $H$ has gave his patent up is zero.

The challenger must be indifferent between the decision of entry or no entry:

$$
\begin{gathered}
\mu\left(\alpha_{h} / \bar{C}\right)\left[\Pi^{h}\left(\beta\left(I_{h}^{*}\right)\right)-I_{h}^{*}-a_{E}\right]+\left(1-\mu\left(\alpha_{h} / \bar{C}\right)\right)\left(\Pi^{\ell}\left(\beta\left(I_{\ell}^{*}\right)-I_{\ell}^{*}-a_{E}\right)=0\right. \\
\mu\left(\alpha_{h} / \bar{C}\right)=\frac{a_{E}+I_{\ell}^{*}-\Pi^{\ell}\left(\beta\left(I_{\ell}^{*}\right)\right)}{\Pi^{h}\left(\beta\left(I_{h}^{*}\right)\right)-I_{h}^{*}-\left(\Pi^{\ell}\left(\beta\left(I_{\ell}^{*}\right)\right)-I_{\ell}^{*}\right)} .
\end{gathered}
$$

By definition

$$
\begin{aligned}
\mu\left(\alpha_{h} / \bar{C}\right) & =\frac{\pi_{H}\left(\bar{C} / \alpha_{h}\right) \rho}{\pi_{H}\left(\bar{C} / \alpha_{h}\right) \rho+\pi_{H}\left(\bar{C} / \alpha_{\ell}\right)(1-\rho)} \\
& =\frac{\rho \pi_{H}}{\rho \pi_{H}+(1-\rho)} .
\end{aligned}
$$

We can substitute (26) in (27) and then:

$$
\begin{gathered}
\frac{\rho \pi_{H}}{\rho \pi_{H}+(1-\rho)}=\frac{a_{E}+I_{\ell}^{*}-\Pi^{\ell}\left(\beta\left(I_{\ell}^{*}\right)\right)}{\Pi^{h}\left(\beta\left(I_{h}^{*}\right)\right)-I_{h}^{*}-\left[\Pi^{\ell}\left(\beta\left(I_{\ell}^{*}\right)\right)-I_{\ell}^{*}\right]} \\
\Leftrightarrow \pi_{H}=\frac{1-\rho}{\rho} \frac{a_{E}+I_{\ell}^{*}-\Pi^{\ell}\left(\beta\left(I_{\ell}^{*}\right)\right)}{\Pi^{h}\left(\beta\left(I_{h}^{*}\right)\right)-I_{h}^{*}-a_{H}} .
\end{gathered}
$$


As $\rho \in] 0,1\left[\right.$ and $\pi_{H}$ must be smaller than 1 we obtain

$$
\begin{gathered}
\pi_{H}<1 \Leftrightarrow(1-\rho)\left(a_{E}+I_{\ell}^{*}-\Pi^{\ell}\left(\beta\left(I_{\ell}^{*}\right)\right)<\rho\left[\Pi^{h}\left(\beta\left(I_{h}^{*}\right)\right)-I_{h}^{*}-a_{E}\right]\right. \\
\Leftrightarrow \rho>\rho^{*} .
\end{gathered}
$$

We have demonstrated that for $\rho>\rho^{*}$, and if $\Pi^{h}\left(\beta\left(I_{h}^{*}\right)\right)<\Pi^{h}\left(\beta\left(I^{o}\right)\right)-a_{H}$, there exists a semi-separating equilibrium which is, for the incumbent, to give his patent up when the market is not favorable, and to randomize his renewal decision when the market is favorable.

The challenger decides to enter the market if it observes that the incumbent keeps his patent in force, because it knows that the market is good. But, when it observes that the patentholder doesn't pay the renewal fee, it randomizes its entry decision, because it cannot infer any information.

We can find another semi-separating equilibrium with a similar proof: when the demand is good, the incumbent always gives his patent up, whereas when the demand is bad, he randomizes his decision to pay for $\rho<\rho^{*}$ and if $\Pi^{\ell}\left(\beta\left(I_{\ell}^{*}\right)\right)<\Pi^{\ell}(0)-a_{H}$. This equilibrium has not a strong economic meaning.

With the same proof, we can show that some semi-separating equilibria cannot exist:

$\rightarrow$ if the incumbent decides to pay the renewal fee when the market is not favorable, and chooses to pay or not with some probability when the market is favorable, we find that $\operatorname{Prob}\{e / C\}>1$. It is impossible to reach an equilibrium.

$\rightarrow$ if the incumbent decides to pay the renewal fee when the market is favorable and to pay or not with some probability when the market is not favorable, we find that $\operatorname{Prob}\{e / C\}<0$. Such a result is also impossible. 